\title{
Could Scutellaria barbata D. Don be used for treating lung cancer and SARS-CoV-2?
}

\author{
Siukan Law, ${ }^{1}$ Albert Wingnang Leung, ${ }^{2}$ Chuanshan $\mathrm{Xu}^{3}$ \\ ${ }^{1}$ Department of Science, School of Science and Technology, Hong Kong Metropolitan University, Ho Man \\ Tin, Kowloon, Hong Kong; ${ }^{2}$ School of Nursing, Tung Wah College, Ho Man Tin, Kowloon, Hong Kong; \\ ${ }^{3}$ Key Laboratory of Molecular Target and Clinical Pharmacology, State Key Laboratory of Respiratory \\ Disease, School of Pharmaceutical Sciences and Fifth Affiliated Hospital, Guangzhou Medical University, \\ Guangzhou, China
}

\section{Dear Editor,}

Scutellaria barbata D. Don (SBD) is a perennial herb and belongs to the "Lamiaceae" family. This is widely used in China for a long time as Traditional Chinese Medicine (TCM). Based on the TCM theory, SBD is in the category of "Heat-Clearing". Its functions are to remove heat and detoxification, disperse blood stasis and diuresis. ${ }^{1}$ Lung cancer is a leading cause of death worldwide and has an estimated 2.09 million deaths in 2018 according to the World Health Organization (WHO). ${ }^{2}$

Growing evidence has shown that the SBD possessed antiinflammatory and anti-cancer properties. The functional components in SBD including phenolics, flavonoids, chlorophylls, carotenoids, carotenoids, and chlorophylls which inhibited the production of lipopolysaccharide-induced nitric oxide, prostaglandin $\mathrm{E}_{2}$, interleukin-6, and interleukin-1 $\beta$, as well as the expressions of phosphor extracellular signal-regulated kinase and phosphor-c-Jun N-terminal kinase (p-JNK) on RAW 264.7 cells. ${ }^{3}$ Yin et al. report-

Correspondence: Siukan Law, Department of Science, School of Science and Technology, Hong Kong Metropolitan University, Ho Man Tin, Kowloon, Hong Kong, China.

E-mail: siukanlaw@hotmail.com

Key words: Scutellaria barbata D. Don; traditional chinese medicine; lung cancer.

Conflict of interest: The author has no conflict of interest to declare.

Availability of data and materials: All data generated or analyzed during this study are included in this published article.

Ethics approval and consent to participate: Not applicable.

Informed consent: Not applicable.

Received for publication: 14 September 2021.

Revision received: 27 October 2021.

Accepted for publication: 27 October 2021.

This work is licensed under a Creative Commons Attribution NonCommercial 4.0 License (CC BY-NC 4.0).

(C) Copyright: the Author(s),2021

Licensee PAGEPress, Italy

Infectious Diseases and Herbal Medicine 2021; 2:163

doi:10.4081/idhm.2021.163 ed the ethanol extracts of SBD inhibited the growth of A549 human lung cancer cell line. Its mechanism involved cell apoptosis such as DNA damage, cell cycle control, nucleic acid binding, and protein phosphorylation. The cytotoxic effects of SBD on A549 cells with $\mathrm{IC}_{50}$ of $0.21 \mathrm{mg} / \mathrm{mL} .{ }^{4}$ Chen et al. found that the SBD in lung cancer was related to the P38/SIRT1-regulating cell apoptosis through G2/M phase arrest and ER stress, intrinsic mitochondrial, and extrinsic FAS/FASL-mediated pathways. SBD reduced the lung tumor size with decreased proliferation and angiogenesis, as well as increased apoptosis of lung cancer cells. ${ }^{5}$ Gong et al. also indicated the SBD inhibited the lung tumor growth of Lewis-bearing C57BL/6 mice through modulating the immune function which provided the possible application of immunotherapy for the treatment of Non-Small-Cell Lung Cancer (NSCLC) in an early and advanced stage to further human clinical study. ${ }^{6}$

SBD is TCM and its formulation revealed good cytotoxicity on lung cancer. The TCM formulation include $0.5-1.5 \mathrm{~g} \mathrm{SBD}, 0.5-1.5 \mathrm{~g}$ Prunellae spica, $0.5-1.5 \mathrm{~g}$ Antrodia camphorata, $0.5-1.5 \mathrm{~g}$ Curcumae rhizome, 0.5-1.5g Paeoniae suffruticosae cortex, 0.5$1.5 \mathrm{~g}$ Patriniae herba, 0.5-1.5g Ixeris herba, and 0.5-1.5g Phellinus linteus. Tsai et al. indicated that this TCM formulation inhibited lung cancer. Treatment dosage was typically 4 to $300 \mathrm{~g}$ per day for the average human. ${ }^{7}$ Another research from Wang focused on a TCM prescription named Lian-Jia-San-Jie-Fang (LJSJF), which synergistically regulated the Epidermal Growth Factor Receptor (EGFR) or p53 signaling pathways. It downregulated in EGFR and downstream signaling targeted mTOR and p38 MAPK to suppress the growth of lung cancer. ${ }^{8}$

Coronavirus disease 2019 (COVID-19) is caused by SARSCoV-2 infection, which has been spread rapidly across the world. It is mediated by the recognition of a Receptor-Binding Domain (RBD) between the S protein and Angiotensin-Converting Enzyme 2 (ACE2) receptor on the host cell surface, and the activation of $\mathrm{S}$ protein bind to TMPRSS2 transmembrane serine protease 2 that is an inhibitor to prevent the virus invasion. ${ }^{9}$ In early 2021 , Huang et al. reported SBD may effectively prevent SARS-CoV-2 infection and replication through inhibiting $\mathrm{M}^{\text {pro }}$ and TMPRSS2 protease activities. ${ }^{10}$

The above information demonstrates that Scutellaria barbata D. Don is a possible candidate in Chinese medicine for treating lung cancer and SARS-CoV-2 as it possesses anti-inflammatory, anti-cancer, and anti-viral properties. According to the TCM theory, SBD functions are to remove heat and detoxification within the body. Its TCM formulation and prescription are effective to inhibit lung cancer and enhance the immune system. However, much more works need to be done, especially for the multiple TCM formulation on the safety assessment of human clinical trials. SBD combined with the usage of other Chinese medicine may be a good 
choice to increase its functions or properties to treat various cancers and respiratory diseases.

\section{References}

1. Puri BK, White N, Monro JA. The effect of supplementation with Scutellaria baicalensis on hepatic function. Med Hypotheses 2019;133:109402.

2. Sung H, Ferlay J, Siegel RL, et al. Global Cancer Statistics 2020: GLOBOCAN Estimates of Incidence and Mortality Worldwide for 36 Cancers in 185 Countries. CA Cancer J Clin 2021;71:209-49.

3. Liu HL, Kao TH, Shiau CY, Chen BH. Functional components in Scutellaria barbata D. Don with anti-inflammatory activity on RAW 264.7 cells. J Food Drug Anal 2018;26:31-40.

4. Yin $\mathrm{X}$, Zhou J, Jie C, et al. Anticancer activity and mechanism of Scutellaria barbata extract on human lung cancer cell line A549. Life Sci 2004;75:2233-44.

5. Chen CC, Kao CP, Chiu MM, Wang SH. The anti-cancer effects and mechanisms of Scutellaria barbata D. Don on CL1-
5 lung cancer cells. Oncotarget 2017;8:109340-57.

6. Gong T, Wang CF, Yuan JR, et al. Inhibition of tumor growth and immunomodulatory effects of flavonoids and Scutebarbatines of Scutellaria barbata D. Don in LewisBearing C57BL/6 Mice. Evid Based Complementary Altern Med 2015;2015:630760.

7. Tsai HH. Composition for preventing cancer and treating cancer and intensifying the effects of other anticancer drugs. US Patent 2014: US9789153B2.

8. Wang Q, Acharya N, Liu Z, et al. Enhanced anticancer effects of Scutellaria barbata D. Don in combination with traditional Chinese medicine components on non-small cell lung cancer cells. J Ethnopharmacol 2018;217:140-51.

9. Hoffmann M, Kleine-Weber H, Schroeder S, et al. SARS-CoV2 cell entry depends on ACE2 and TMPRSS2 and is blocked by a clinically proven protease inhibitor. Cell 2020;181:27180.

10. Huang ST, Chen Y, Chang WC, et al. Scutellaria barbata D. Don inhibits the main proteases (Mpro and TMPRSS2) of severe acute respiratory syndrome Coronavirus 2 (SARS-CoV2) Infection. Viruses 2021;13:826. 